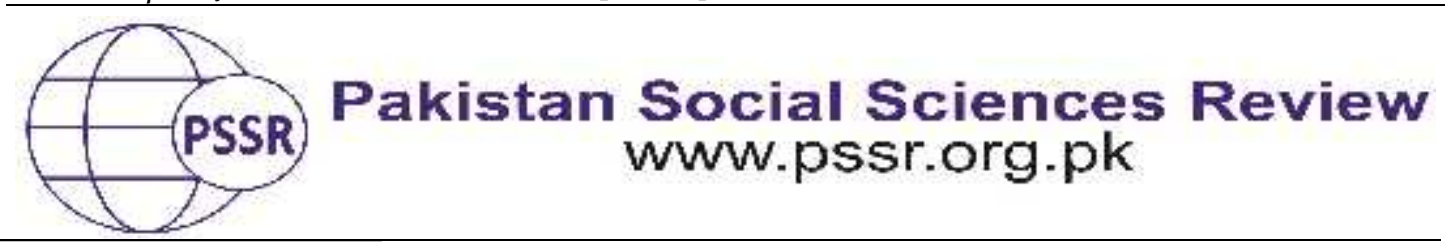

RESEARCH PAPER

\title{
Universal Grammar (UG) Access in the Acquisition of Literacy Skills: Evidences from the Undergraduate (BS- English) Students' Knowledge of Punctuations
}

\author{
Jasim Khan ${ }^{1}$ Dr. Abdul Hamid ${ }^{2}$ Dr. Imdad Ullah Khan ${ }^{3}$
}

1. Scholar, Department of English \& FL, University of Swat, KP, Pakistan

2. Assistant Professor, Department of English \& FL, University of Swat, KP, Pakistan

3. Assistant Professor, Department of English \& FL, University of Swat, KP, Pakistan

\begin{tabular}{|c|c|}
\hline & \\
\hline $\begin{array}{l}06,2021 \\
: \\
021 \\
021\end{array}$ & $\begin{array}{l}\text { This study aims to investigate the gap between the explicit and } \\
\text { implicit knowledge of L2 learners of English language at } \\
\text { undergraduate level within the framework of Universal } \\
\text { Grammar (UG). The process of error analysis used to find UG } \\
\text { access in the acquisition of literacy skills (punctuations). The }\end{array}$ \\
\hline $\begin{array}{l}\text { Keyv } \\
\text { Expl } \\
\text { Knov } \\
\text { Impl } \\
\text { Knov } \\
\text { Inter } \\
\text { Univ } \\
\text { Gran }\end{array}$ & $\begin{array}{l}\text { population of this study comprised of the students of BS- } \\
\text { English } 4^{\text {th }} \text { semester. The total number of participants was } 60 \text {. } \\
\text { The data was collected through multi-stage, sampling } \\
\text { techniques; essay, descriptive questions/answers, MCQs and } \\
\text { true/false, then a representative sample group was selected for } \\
\text { the study. The collected data were analyzed through mean } \\
\text { scores, standard deviation and through the analysis of their } \\
\text { writing with the help of SPSS version } 16 \text {. The result reveals that }\end{array}$ \\
\hline $\begin{array}{l}\text { *Corresponding } \\
\text { Author }\end{array}$ & $\begin{array}{l}\text { in responding to descriptive questions which can be } \\
\text { an evidence of gap between their implicit and explicit } \\
\text { ge. The gap that exists between the explicit and implicit } \\
\text { ge of punctuation on the part of the learners may } \\
\text { be related to Universal Grammar (inter-language)and } \\
\text { may be counted as an evidence of UG access in the } \\
\text { on of literacy skills (punctuations).A further extensive } \\
\text { required to verify the results with a large number of } \\
\text { ants. }\end{array}$ \\
\hline
\end{tabular}

\section{Introduction}

Error analysis is an alternative to CA (Contrastive Analysis). Due to the emergence of error analysis, the contrastive analysis does not succeed to sustain its significance. According to Larsen (1991), an error is actually a standardized deviation in structure that clearly reveals the learners' linguistics knowledge of language. Moreover, Corder (1981) has urged that those errors which are found in 
the speech of the learners, are the deviations in structure from that of the native speakers', but usually these errors are considered as the features of learner's speech attained at the development stages of language learning. Additionally, errors are committed by the learners due to lack of learners' linguistic competence.

Additionally, Corder (1967) as cited in Ellis (1994) claimed that for the second language learner, the knowledge of grammar is considered important, but difficult to master it properly. The errors made by learner indicates an ongoing process in the mind of the learner, thus the learner has not yet mastered learning second language. Analyzing the errors that are committed by the second language learner would be the best way to indicate the right level of proficiency in the target language which is acquired at a particular time.

\section{Implicit and Explicit Knowledge}

Reber (1993) defines implicit learning as an unconscious attempt to acquire the knowledge and to learn without the requirement of explicit knowledge about what was required. It is clear that implicit learning is a cognitive process which is working on itself.

However, Dienes and Altumann (1997) found that whenever the participants were using their own knowledge in which they were not good enough or a domain which was unfamiliar to them, so their surety related to accuracy would be not that much high as they had in a domain which was familiar to them. Conclusively, when a learner is exposed to the examples of artificial grammatical structure, they may not be able to express a particular grammatical structure.

Furthermore, language learning is reflected through explicit and implicit knowledge in second language (L2) acquisition. The implicit and explicit distinction is used for the description of knowledge and that knowledge is taken to be a view towards a proposition which is accurate. The proposition itself signifies an attribute to some essence. According to the Representational Theory of Mind (RTM), "knowledge is a propositional attitude" (Field 1978; Fodor 1978). For instance, if I have knowledge of a fact (e.g. an animal in front of me is a cow) then, according to this view, this is because of my internal knowledge that the use of " $\mathrm{I}$ " represents a fact. So, knowledge can vary; it may be Explicit or Implicit. The representation is explicit and the aspect used in functional representation is implicit knowledge. In addition to it, Schacter (1987) expressed that when you are performing a task on the basis of your prior experiences and no conscious mind or intentional recognition of those previous experiences are involved, it is known to be implicit knowledge. On the other hand, explicit knowledge is revealed when you are performing a task on the basis of your previous experiences due to the involvement of conscious recognition of prior experiences.

Whereas, according to Krashan (1977), explicit knowledge is playing a vital role because it is available to the monitor production mechanisms to enable the 
learners to look after their performance or to lead them to change their performance. If there is any sort of fault, they can correct it consciously. As Bialystok (1982) suggested that L2 learners can differentiate the implicit and explicit knowledge when the different performance tasks are probably induced.

Based on the above discussion and empirical evidences, the researchers intended to investigate the explicit and implicit knowledge of students' learning English as a second language (L2) with the aim to identify the areas for improvement in language learning.

\section{Literature Review}

This portion deals with the review of the knowledge/information that exists on the research topic. It provides the readers a very easy access for research which are applicable, meaningful and useful for researchers to finalize research project. It provides basic guidelines for the researchers at the start and help the researcher to find gaps for purpose of research project.

Corder (1974) pointed out that the study of errors is a method to find out language learning process. It seems like the process that involve in mother language acquisition. This not only providing the information about the developmental process, but also an insight of the language acquisition process. While, Richards (1992) demonstrated that the investigation of errors that are utilized so as to (1) Identify those methodologies the students adopt in second language instructing, (2) Identify what are the causes of student's errors, that they are committing and finally (3) get that information where the learners have difficulties in language learning process and apply certain strategies in the improvement of instructing materials. As Sharma (1980) claimed that error analysis has the potential to teach in a remedial sense. He further explained his statement that if a teacher adopts a particular strategy he should also have to focus on the students learning process that either such strategy is functioning or not.

Furthermore, Norish (1983) considered errors as a standardize diversion that occurs due to the lack of knowledge or get the incorrect knowledge, however, the errors that are committed by the learner in a context, there would be two processes ongoing either the learning process or acquisition process. According to Hendrickson (1987) errors are 'Signal' that refers to a real learning procedure taking place and this demonstrates that the students have not yet fully developed their proficiency materials in second language learning.

However, Brown (1994) claimed that the analysis of error emphasizes the importance of error in learner's interlanguage system. As Selenker (1972) stated that inter-language refers to the systematic knowledge of second language which is neither the learner's L1 nor L2, but having its own rule which is independent of both L1 and L2. In addition to it,Corder (1967) explained, inter-language is a system that plays a role of intermediation between the L1and L2. When a learner is learning a 
second language, the learner develops his/her own system of rules which neither follows the rules of L1 nor L2; such a system (third language system) which has its own sentence structure, vocabulary, morphology and grammar etc. It is a kind of lingua franca in a sense. As indicated by Chomsky's (1965) perspective on first language acquisition, he recommended that simply like a child acquiring his/her mother tongue, generally the language contains in more or less fixed syntactic pattern or not following what their parents trying to teach to their child and the child is using its own structure of language on the basis of his experience. Therefore, the second language learner may have an "Inbuilt Syllabus" according to that syllabus the language system is acquired and which is autonomous of the order of classroom syllabus or the schedule which is designed for the learners of second language.

However, Ellis (1985) mentioned that Inter-language is a system in which the learner is not using a specific set of rules; whenever, he or she is performing the same function. On one occasion the learner is using one rule and on another occasion a different rule. Instead of a uniform way, which is similar for each learner to develop a system. The learners find another way for themselves to follow the course of development. There are three noteworthy kinds of errors in the second language acquisition based on the learner's spoken and written performance.

\section{Intra-lingual Errors}

As indicated by Richard (1974) the errors that are produced by the learners not because of the first language interference, but overgeneralization based on the limited exposure to the second language. In overgeneralization the learner generally creates one deviant structure in place of two regular structure.

For example, "He can plays", "We are hope", "It is occurs".

\section{Inter-lingual/transfer Errors:}

Selinker (1974) noted that due to the negative interference of first language habits, these errors are produced. He further stated that when the second language learners write or speak in second language, they think in their first language and use a direct translation of it.

\section{Developmental Errors}

According to Richards (1971) "errors occurring when learners' attempts to build up hypothesis about the target language on the basis of limited experience".

Dulay and Burt (1974) classified learner's errors into three broad categories:

1. Developmental Errors: these errors are produced by the learners based on similarities with first language. 
2. Interference Error: as result of the first language interference, these errors are produced by the learners which reflect the structure of first language.

3. Unique Errors: these Errors are produced by the learners which are neither similar to developmental errors nor interference errors.

Stenson 1974 as cited in Karra, 2006 suggested another type of error which he called Induced Error, which are produced by the learners as a result of incorrect instruction of that language. So, Hendrickson (1980) observed that "it is virtually impossible to avoid errors when learning any new skill, particularly when learning a foreign language". Just as George (1972) mentioned that when the child is making errors they have called it, this is a "transitional form" of a child learning a language, but when the second language learners are committing errors they have been calling it, it is the "unwanted form" of the language.Chomsky's viewed that a child can generate language through innate universal structures. This is the way the errors advances progress and improvement in learning. The behaviorists' model is presently substituted by the mentalists' one and gratitude to this new origination the error is at last observed as something positive and as an issue.

Whereas, Sercombe (2000) has explained that there are three main objectives to describe error analysis. The first one, is to discover the stage that up to what extent the learner has mastered the skills of second language and how much he/she has the understanding about the target language. Second, to investigate the reasons behind the problems that learners are facing while learning a second language and the third one is to know the way that how language is learned.

In this study, the researchers were interested in finding the relationship between the explicit and implicit knowledge of the respondents that either the implicit and explicit knowledge are the same or not. The researchers were also interested to understand the reasons that either the respondent don't have the adequate knowledge about punctuation implicitly or they are having the implicit knowledge about punctuation, but they are unable to present or failed to express their knowledge explicitly. Thus, the researchers were interested in finding the reasons of errors in punctuation.

\section{Material and Methods}

The present study comprising of locale of the study, sample size, tools for data collection, procedure of data collection \& pilot study. For the purpose of carrying out this research, the researchers have used mixed methodology. It is partly quantitative and partly qualitative in nature. Data collection has been done through quantitative while the analysis of collected data through quantitative and qualitative method.

\section{Locale of the Study}


The data were collected from higher educational institutions located in district Swat and Malakand. Two universities and one college was selected for data collection.

\section{Sample Size}

The population of this study comprised of the students of BS-English $4^{\text {th }}$ semester. The students of $4^{\text {th }}$ semester in the discipline of English who have studied the subject of the "Foundation of English Grammar" as a subject. The total number of participants were 60. The students were conveniently selected from each institution. Both male and female students participated in carrying out this study. All of the participants were Pashtu speakers and were using English as medium of communication in the institutions. All of the students had different background of schools and colleges, however all of them have studied English as a subject at intermediate level.

\section{Tools of Data Collection}

The instrument that were used in this study consisted of sections i.e. essay, subjective question answer, multiple choice questions, true/false statements.

The first section of test that used in the study was essay written by 60 participants. All of the essays given in the test were typical and general, because of the availability of maximum information to the students regarding the given essays and were easy for the participants to write more about the topics. The participants had to develop essay of minimum 250 words. The following topics were given to them for essay writing task:

- Child Labor

- The role of Media in Social awareness

- Advantages and Disadvantages of Mobile Phone

- A Morning Walk

- My Home Town

- Pakistan

The second section of test was descriptive in nature. The respondents had to attempt all the 9 questions which were given in this part of the test.

The third section of test that used in the study was multiple choice questions and the participants had to select the correct option from the given four options. There were twelve MCQs in this section.

The fourth section of test used in the study was to mark those sentences in which the punctuations are correctly used. There were 10 sentences in this section of the test. 


\section{Procedure of Data Collection}

The data of errors organized through the following process that specified by Corder (1974):

- Collection of sample of errors

- Identification of errors

- Description of errors

The tests were divided into four parts:

1. The essay part was distributed among the students and they were asked to select the topic on which they could write more and had much information about. They had to write an essay of minimum 250 words. The time given for writing essay was 25 minutes.

2. Then answer questions section of test was distributed among the participants and the duration of time for it, was 20 minutes.

3. After that multiple choice questions were distributed among the participants and the participants had to attempt this section in the duration of 10 minutes.

4. Lastly, the forth section of the test was distributed among the participants in which they had to mark the correctly punctuated sentences. The time given for this section was 5 minutes.

\section{Results and Discussion}

All the collected data were initially analysed manually and then help was taken from SPSS version 16 for the analysis of the data through mean scores and standard deviations. The details of the results and interpretations are as follow;

Table 1

Accuracy in the Use of Full Stop

\begin{tabular}{cccc}
\hline Correct use of Full Stop & N & Mean & Std. Deviation \\
\hline Essay & 60 & 84.8833 & 12.88924 \\
\hline MCQs & 60 & 21.67 & 28.416 \\
\hline True / False & 60 & 73.33 & 44.978 \\
\hline Question Answers & 60 & 38.33 & 42.918 \\
\hline
\end{tabular}




\section{Explanation}

The above table (1) shows the participants' use of full stop while attempting the essay, MCQs, true / false and question answers. The mean score 84.8833 with standard deviation 12.889 shows that majority of the respondents used stop correctly in essay writing. However, on the other hand, attempting the question answers section instead of having knowledge or implicit knowledge, the respondents failed to express their knowledge explicitly. This is what the above table shows that the mean score is 38.33 with standard deviation 42.918 of full stop. Which is a very low as compared to the mean score 84.8833 with standard deviation 12.88924 while responding to the essay type questions. The responses of the students while attempting the true/false section of test. The result of the T/F as shown in the above table the mean is 73.33 with standard deviation 44.918 , but this could be considered partly accidental or there is a possibility of accident. However, the other hand, MCQs attempted by the respondents again majority of them failed to reflect their implicit knowledge employed in essay type questions, to use their implicit knowledge. The means of pull stop in MCQs is 21.67 with standard deviation 28.416.

Similarly, there are evidences of participants' describing between implicit and explicit knowledge of full stop as shown by the following example.

\section{Respondent No.1}

For example, a respondent has correctly used punctuation mark (full stop) at the end of an indirect sentence while attempting to write the essay on "what are the advantages and disadvantages of mobile phone", in the following example:

(1) "It is up to the use that how he is using a mobile phone."

In the example (1), the respondent has correctly used a punctuation mark (full stop) at the end of an indirect sentence while attempting the essay. However, on the other hand in the question answer section of the test the respondent failed to respond correctly to the question cited in (1.1) that is related to the use of full stop at the end of an indirect question.

\section{(1.1) Which punctuation mark is used at the end of an indirect question?}

Not only this, but the respondent also failed to mark the correct answer of the MCQ (1.2) in MCQs section of the test about the use of full stop at the end of an indirect sentence, which indicates that the respondents implicitly knows that full stop is used at the end of an indirect sentence.

(1.2) They asked what time the department store would open
a)
?
b).
c) :
d) : 
Thus the incorrect option (a) was chosen by the respondent and once again the respondent failed to choose the correct option in the above example (1.2).

Hence, the above discussion about the respondent performance indicates that the respondent responded differently at each section of the test. One thing that is clear from the response of the respondent that he/she correctly used the mark (full stop) in the essay while in the descriptive questions about the mark, the responded failed to give an appropriate and correct response. This indicates that the respondent's knowledge about the punctuation mark (full stop) is implicit.

Table 2

Accuracy in the Use of Semi Colon

\begin{tabular}{cccc}
\hline Correct use of semi colon & N & Mean & Std. Deviation \\
\hline Essay & 60 & 10.0000 & 30.51286 \\
\hline MCQs & 60 & 35.8333 & 20.43000 \\
\hline True / False & 60 & 38.5667 & 31.48035 \\
\hline Question Answers & 60 & 22.9000 & 29.02359 \\
\hline
\end{tabular}

\section{Explanation}

The above table shows the participants use of semi colon while attempting the essay, descriptive question answers, MCQs and true/false. The mean score 10.00 and standard deviation 30.51286 show that most of the students failed to use semi colon correctly while attempting the essay. In the question answers section of test, the mean of semi colon is 22.900 with standard deviation 29.02359. This also shows that the respondents do not know much about semi colon and that is why failed to describe the descriptive questions regarding semi colon.

On the other hand, the mean score is 35.8333 with standard deviation 20.43000 of semi colon while responding to MCQs. It means that the respondents do not know much semi colon to attempt correctly. The response to the MCQs can be partly accidental and partly backed by implicit and explicit knowledge of the respondents. The mean of semi colon is 38.5667 with standard deviation 31.48035 in $\mathrm{T} / \mathrm{F}$ section. The responses of the participants are correct up to some extent but they were not good enough.

\section{Respondent No.2}

Another respondent responded to the questions regarding semi colon and colon while attempting the question answers section of test. The respondent successfully used his explicit knowledge and rightly described the question (5) of semi colon explicitly.

(5) To separate a series of loosely related clause, which punctuation is used? Give an example. 
The response that was given by the respondent to the question (5) as, "Semi colon is used to separate a series of loosely related clause" the respondent responded to the question (5) correctly to describe it explicitly, but the respondent failed to use his explicit knowledge to give an example of semi colon. It indicates that the respondent unable to use the explicit knowledge practically and did not give an example in which semi colon is used. This means that the respondent was not fully aware of the rules that where semi colon is used. The respondent failed to represent his explicit knowledge practically in writing. This also indicates that the respondent was not interested in giving an example of semi colon or the lack of attention or experience of using semi colon practically. The respondent not only failed to give an example of semi colon, but he/she did not use semi colon in the whole writing of the essay. The respondent did not use semi colon in the writing while attempting the essay on the, "Advantages and disadvantages of Mobile phone." For example, a sentence (5.1) is taken from the essay that was written by the respondent and there is need of using semi colon, but the respondent did not use semi colon in it.

(5.1) "There are various advantages of using mobile phone primarily, it is used for communication, for transfer of information. This is the first most benefit of mobile phone"

The respondent did not use semi colon in (5.1). If we put semi colon in the above sentence (5.1), then the above sentence would be like as, "there are various advantages of using mobile phone; primarily, it is used for communication, for transfer of information. This is the first most benefit of mobile phone".

When the respondent responded to the MCQ (5.2) while attempting the MCQs section of the test. The respondent chose the right option.

He was a and we respected him.

a) brave young man; b) brave, young man; c) brave, young man,

The respondent not only used the implicit knowledge properly, in responding to the above MCQ (5.2), but also appropriately responded to another MCQ (5.3) while attempting the MCQs section of the test.

Which answer uses the semi colon correctly?

a) The traffic on bypass was horrible, I decided to wait;

b) The traffic on bypass was horrible; and I decided to wait.

c) The traffic on bypass was horrible I decided to wait;

The respondent appropriately responded and marked the option (b), which is the correctly punctuated option specifically about the use of semi colon. 
The respondent once again failed to use the knowledge of partly accidental and to mark a sentence (5.4) properly while attempting the true/false section of the test.

\section{(5.4) I like cows; however, I hate the way they smell.}

This is what we know from the rules of semi colon, that there would be use semi colon (;) before certain words like, "therefore and however." Hence, it also indicates that the respondent did not have the adequate knowledge about semi colon. The respondent did not use semi colon in writing implicitly while attempting the essay. He/She failed to use colon in the writing of the essay implicitly.

Hence, the respondent properly described the descriptive question, but he/she did not replicate the explicit performance implicitly about the use of semi colon. The respondent also has identified the appropriate answer of MCQ (5.3), strangely by using his/her implicit knowledge. One thing that we get from the above performance, the respondent needs to have a regular practice of using semi colon in writing and to have a careful attention towards the use of semi colon

Table 3

Accuracy in the Use of Colon

\begin{tabular}{llll}
\hline Correct use of colon & $\mathrm{N}$ & Mean & Std. Deviation \\
\hline Essay & 60 & 20.6667 & 40.42305 \\
MCQs & 60 & 26.4333 & 26.66482 \\
True / False & 60 & 20.9677 & 28.20814 \\
Question Answers & 60 & 21.6667 & 31.30312 \\
\hline
\end{tabular}

\section{Explanation}

The above table 3 shows the respondents use of colon by attempting the essay, question answers, MCQs and true/false. The mean score of colon in essay is 20.6667 with standard deviation of 40.42305 shows that the majority of the students used colon incorrectly while attempting the essay. The respondents not only failed to perform implicitly to attempt colon in the essay, but also failed to express their knowledge explicitly while responding to question answers. The mean is 21.6667 with standard deviation of 31.30312 indicates the response of the respondents toward the of use colon in question/answers which clearly shows that the respondents were not good in the use of colon in both cases; explicitly and implicitly.

The respondents have responded to the use of colon while attempting the MCQs. The mean is 26.4333 with standard deviation of 26.66484 . This shows that majority of the respondents have used colon incorrectly in responding to MCQs and failed to perform properly. The respondents have attempted true/false while responding to colon, the mean is 20.9677 with standard deviation of 28.20814 . It 
reveals that even by using the knowledge of guessing or predictions, the respondents failed to use colon correctly.

\section{Respondent No.3}

Another respondent responded to the question (3) while attempting the question answers section of tests.

(3) What is the difference between colon and semi colon?

The respondent attempted this question and answered that "colon (:) it is a greater pause that list down something. Semi colon (;) it is a weaker pause than colon and explain ideas."

On the other hand, when responded in descriptive question by the respondent, the respondent used semi colon and colon interchangeably in the writing while attempting the essay.

(3.1) "We use different types of social media application that are given; skype, viber,Facebook, twitter, and instegram etc."

The respondent used semi colon instead of colon and failed to use punctuation marks implicitly in the writing while responding to the question (3), the respondent properly described the difference between colon and semi colon.

The same respondent responded to the MCQ (3.2), but the respondent selected the incorrect option, regarding to colon while attempting MCQs section of test.

(3.2) The children were told to bring the following items a pen, a pencil, a ruler and an exercise book.
a) .
b) :
c) ;
d) ,

The (c) option was selected by the respondent which is the incorrect option and the correct option is (b) colon. The respondent repeated the same error again as the respondent has done in the writing while attempting the essay. This reveals that the respondent is practically unaware of the difference between the use of semi colon and colon. The respondent also did not know that colon is used before a "quotation" like for example, the respondent did not respond to a question that is given in the section of tests, to mark right for those sentences in which punctuation marks are correctly used.

(3.3) Bacon says; "reading makes a full man, writing an exact man, speaking a ready man." 
The respondent responded to the (3.3) statement that, "I don't know", which indicates that the respondent has no sufficient knowledge about colon and semi colon.

One thing that is also clear from the above discussion, the respondent is not aware of the importance of punctuation that's why the respondent is not focusing on the use of punctuation marks in his writing.

Table 4

Accuracy in the Use of Comma

\begin{tabular}{cccc}
\hline Correct use of comma & N & Mean & Std. Deviation \\
\hline Essay & 60 & 89.3083 & 14.77237 \\
\hline MCQs & 60 & 46.2333 & 23.96791 \\
\hline True / False & 60 & 28.3333 & 21.50915 \\
\hline Question Answers & 60 & 14.1667 & 18.19830 \\
\hline
\end{tabular}

\section{Explanation}

The above table 4 shows that the participants use of comma while attempting the essay, question answers, MCQs and true false. The mean score 89.3083 with standard deviation 14.77237 shows that most of the students have used comma correctly while responding to the essay. This shows that by the use of comma the respondents have scored strangely, the response of the respondents toward the questions/answers was not satisfactory and they failed to express their implicit knowledge explicitly. In contrast, the response of the students was very high while attempting the essay by using implicit knowledge.

The mean score is 46.2333 with standard deviation 23.96791 shows that up to some extent the respondents have correctly used comma while using their implicit knowledge to attempt the MCQs. The response of the students toward the use of comma while attempting true/false is not satisfactory. The mean of T/F is 28.3333 with standard deviation 21.5091. This shows that majority of the respondents have incorrectly used comma while responding to the true/false.

\section{Respondent No.4}

The respondent responded to the question (2) about the punctuation mark "comma" while attempting the question answers section of test.

\section{(2) Where do we use comma?}

The respondent attempted this question and has given a brief answer to this question. The respondent responded to the question as "we are using comma for a break or at the end of a clause." The responded did not give a comprehensive answer to it, but it is still understandable that the respondent is aware of the use of the mark, that 
it is used for a break. Surprisingly, he added that comma is also used at the end of a clause/sentence.

However, while attempting the essay the respondent did not follow what he said about the use of comma. He neither used comma for a pause/break nor at the end of clause/sentence. The following paragraph is taken from the essay attempted by the respondent on the "Advantages and Disadvantages of Mobile Phone":

(2.1) "Mobile is an electronic device which is used for communication. As from the word it is clear that it is a device which make keeps the whole world movable means that it connects the world as a global village. Mobile phone has many advantages as it communicate the people with one another."

Contrary to what he/she said, the respondent did not use comma at the end of a clause or for a break, but the respondent continually used conjunction "that", to conjoin two clauses without using comma. The respondent not only used conjunction repeatedly in the above paragraph, but he/she used conjunction "that" consistently throughout the whole essay. The respondent did not use comma in his/her writing while attempting the essay. It indicates that the respondent has knowledge about punctuation and was able to use it explicitly, but failed to use comma in the writing of the essay.

The respondent also failed to choose the correct option in (2.1) implicitly in the MCQs section of tests as shown in (2.1).

sentence?

(2.1) Which of these is used to separate short co-ordinate clause of a compound
a) Semi colon
b) comma
c) full stop
d) colon

The incorrect option (a) was chosen by the respondent while attempting the MCQ (2.1).

\section{(2.2) I came, I saw, I conquered.}

(2.3) My aunt who lives in Karachi, is a doctor.

The respondent marked the first sentence (2.2) 'incorrect', despite the fact that it is correctly punctuated. On the other hand, the respondent marked (2.3) 'correct'.

Hence, the respondent is having the lack of practice and attention toward the use of punctuation. It also indicates that the respondents know about the use of comma explicitly, but he/she was unable to replicate it implicitly in writing of the essay. So, there is some intuitive system and it plays an effective role or its effect seems in the performance of the respondent. Thus, the performance of the 
respondent shows that the respondent says one thing and doing something else that is contrary to what he/ she said.

\section{Discussions}

The results from the above tables indicate that the respondents correctly used punctuation marks in the order of comma, full stop, colon and then semi colon while responding to the essays. This shows that the respondents have highly performed and they are good in the use of comma and weak in the use of semi colon.

The Participants have acquired the punctuation as such in order, which is the alternative of the order given in the English language grammar (full stop, comma, semi colon and colon). As mentioned above in portion (2) Chomsky's (1965) perspective on first language acquisition, he recommended that simply like the child acquiring his/her mother tongue, generally the language contains in a more or less fixed in syntactic pattern or not following what his/her parents trying to teach and using his/her own structures of language on the basis of his/her experience. Therefore, the second language learners may likewise have an "Inbuilt Syllabus" according to that syllabus the language system is acquired and which is mostly autonomous of the order of classroom syllabus or the schedule which is designed for the learners of second language. So, the punctuations that have acquired by the participants in such in order, which is mentioned by Chomsky. But it is also supporting the claim of him about the language acquisition process that not only the child acquiring mother tongue by following their own system, while the second language learners' have also their own system to acquire second language and not following the order of classroom syllabus or schedule designed for the second language learners.

The respondents have not performed very well in punctuations while responding to question answers, this is because of their lack of competence knowledge or they failed to express the implicit knowledge as Norish (1989) stated that errors as a standardize diversion that occurs due to the lack of knowledge or get the incorrect knowledge; however, the errors that are committed by the learner in a context, there would be two processes ongoing either the learning process or acquisition process. Hence, the participants did not give any satisfied answer to the questions due to the lack of competence knowledge or having the knowledge about punctuations, but it becomes fossilized or failed to express implicit knowledge explicitly. The study indicates that on one hand attempting the essays the participants have responded correctly to use comma and the respondents got the highest score in comma among the other punctuation marks, but when it comes to the question answers section of the test, the respondents totally failed to respond to such questions and strangely they scored very low in comma as compared to other punctuations. According to James (2001) errors occur because of the unawareness from the linguistic knowledge. 
The result of each table is totally different from others, the respondents performed differently while attempting each section of the test and this shows that the learners neither following the rules of the first language or the second language, but following their own rules which is neither from L1 nor L2 from as mentioned by Corder (1967) that inter-language is a system that plays a role of intermediate between the L1 and L2.When learners are in the process of language learning, the learner develop their own system of rules which is neither following the rules of L1 nor of L2; such a system (third language system) which has its own sentence structure, vocabulary, morphology and grammar etc.

The respondents also did not score well enough in responding to semi colon and colon in each of the test section, because the first thing is that these both were confusing for the respondents having a similar instruction only a slightly difference found between them and also not having enough exposure to the input of these two punctuations. Kaweera (2013) discussed that the errors are not only as the result of the habits of first language interference but also due to the inadequate knowledge or acquisition of the second language. He further stated that there are some rules which are difficult to understand and also there are some exceptions founds and it is hard to keep it and this is what make the respondents confused to respond. This shows that the learners of the second language will pass through certain developmental stages ruled by similar in birth universal principles and there are some nonlinguistic factors and because of it, the second language instruction are not totally acquired proposed by (Chomsky, 1965).

\section{Conclusion}

The focus of this study was to compare the explicit and implicit knowledge of the English language of participants of BS English regarding the use of punctuation marks (full stop, comma, semi colon and colon). The study found that there is a gap between explicit and implicit knowledge of the participants of $4^{\text {th }}$ semester of BS English. The participants sometimes were able to use implicit knowledge explicitly, but sometimes the participants failed to use implicit knowledge explicitly. Sometimes the participants were able to answers the descriptive question explicitly, but they failed to replicate their explicit knowledge implicitly in the writing of the essays. But also sometime the participants properly used punctuation in the writing of the essays while failed to give answers of descriptive questions explicitly. This clearly indicates that there are some features related to inter-language. The frequency of the participants who failed to replicate their explicit knowledge implicitly is more than those who failed to express their implicit knowledge explicitly.

The participants have learnt those rules about punctuation which are easy in nature and have left those which are complex in nature. This is also one of the feature of inter-language, that at the stage of inter-language the learners modify the rules for themselves. 


\section{Recommendations}

In the light of the results of the present study, the following are some of the recommendations that how the second language learners will reduce, overcome or avoid the punctuation errors.

It is recommended that the learners of the second language should be exposed adequately to the rules of punctuation at school or college level. Because at University level punctuation is not taught to participants. As a result, most of the participants do not know the correct use of punctuation. The majority of the participants have just learned the symbols or marks of punctuation but do not know the rules of punctuation and mostly committing errors due to the lack of adequate knowledge about punctuation. So, the punctuation rules should be taught at school and college level properly that the participants should come to know about the rules of punctuation. it will help the participants to minimize the errors of punctuation.

The second recommendation is that the learner should be exposed to adequate input of English language. The learners are suggested to practice writing on regular basis to develop their writing skills.

The third recommendation is that the teacher should have to reconsider their teaching strategies and techniques. The teachers would have to adopt strategies which not only help the participants to learn the rules and to use punctuation correctly, but also to develop the interest of the learners towards punctuation. The teachers need to focus on punctuation during the classroom activities as well as in examinations continuously. Additionally, the teachers also need to give more importance to the correct use of punctuation in the course of writing because it affects the meaning when a punctuation mark is used incorrectly.

The forth recommendation is that there might be similarities and differences between the mother tongue and the target language (L2). The teachers need to help the participants in such areas where mother tongue interferes.

The fifth recommendation is that majority of the participants are using semi colon and colon interchangeably. So, the teachers have to teach the rules properly. It will help the participants to differentiate between semi colon and colon and will learn the correct use of both.

The last point is that most of the participants know the rules implicitly (their competence knowledge) as seen in previous portion, the participants use comma correctly. But they failed to express their implicit knowledge explicitly when they were responding to attempt the question answers section of the test. The responses of the participants were found unexpectedly very low. So, there should be a proper practice of writing on regular basis that the participants not only become able to use punctuation implicitly, but also they also they will come to know about the rules of punctuation to respond explicitly. Hence, the participants first have to learn the 
rules of punctuation and then the practice of using punctuation correctly in their writing, as a result the participants will not only able to respond implicitly but will also be able to respond explicitly. 


\section{References}

Bialystok, E. (1982). On the relationship between knowing and using forms. Applied Linguistics, 3, 181-206.

Brown, D. B. (1994). Principles of language learning and teaching. Third edition. New Jersey: Prentice Hall.

Corder, S. P. (1967). The significance of learner's errors. International Review of Applied Linguistics, 5 (4), 161-170.

Corder, S.P. (1974). Error Analysis. Techniques in Applied Linguistics. Oxford: Oxford University Press

Corder, S.P. (1981). Error analysis and interlanguage. Oxford: Oxford University Press.

Chomsky, N. (1965). Aspects of the theory of syntax. THE MLT PRESS. Massachusetts Institute of Technology. Cambridge, Massachusetts.

Dulay, C., \& Burt, K. (1974). Error and strategies in child second language acquisition. TESOL Quarterly, 8, 129-138.

Dienes, Z. \& Altmann, G. (1997) Transfer of implicit knowledge across domains?

How implicit and how abstract? In: How implicit is implicit learning?, ed. D. Berry. Oxford University Press.

Ellis, R. (1985b). Understanding Second Language Acquisition. Oxford: Oxford University Press.

Ellis, R. (1994). The study of second language acquisition. London: Oxford University Press.

Field, H. (1978) Mental representation. Erkenntenis 13:9-61.

Fodor, J. A. (1978) Propositional attitudes. The Monist 61:501-23.

George, H.V. (1972). Common Errors in Language Learni ng: Insight from English. Newbury House Publishers, Inc., 68 Middle Roa d, Rowley Massachusetts 01969.

Hendrickson, J. M. (1980). Error Correction in foreign language teaching: Recent theory, research and practice. In K. Croft (Ed.), Reading on English as a Second Language ( $2^{\text {nd }}$ ed.). Combridge, MA: Winthrop Publisher.

Hendrickson, J.M. (1987). Error correction in foreign language teaching: Recent theory, research and practice. In M.H. Long \& J.C. Richards (eds.), Methodology in TESOL: A book of readings. Boston: Heinle \& Heinle. P.357 
James, C. (2001). Errors in language learning and use: Exploring error analysis.Beijing: Foreign Language Teaching and Research Press.

Krashen, S. (1977). 'Some issues relating to the Monitor Model' in H.D. Brown, C.A. Yorio and R.H. Crymes 9eds.): on TESOL ,77. Washington DC: TEESOL, pp. 14458

Kaweera, C. (2013). Writing error: A review of interlingual and intralingual interference in EFL context. English LanguageTeaching, 6 (7), 9-18.

Larsen-Freeman, D. (1991). An introduction to second language acquisition research. London: Longman.

Norish, J. (1983). Language Learners and their errors. London: Modern English Publications.

Richards, J. C. (1971). A non-contrastive approach to Error Analysis. English Language Teaching Journal, 25, 204-219.

Richards, J. C. (1974). Error Analysis: Perspectives on second language acquisition. London: Longman.

Richards, J.C. (1992). Dictionary of language teaching and applied linguistics. Essex: Longman.

Reber, A.S. (1993). Implicit learning and tacit knowledge: An essay on the cognitive unconscious. Oxford, UK:Oxford University Press.

Selinker, L. (1972). Inter-language. IRAL 10, 3:209-23.

Selinker, L. (1974). Inter-language. In J. Richards (Ed.), Error analysis: Perspectives on second language acquisition (pp. 31-54). Essex: Longman.

Stenson, N. (1974). Induced Errors. In J. Schumann and N. Stenson (eds.) New Fronteirs in Second Language Learning. Massachusetts: Newbury House Publishers.

Schacter, D. L. (1987). Implicit memory: History and current status. Journal ofExperimental Psychology: Learning, Memory, and Cognition 13:501-18.

Sercombe, P. (2000). Learner language and the consideration of idiosyncrasies by students of English as a second or foreign language in the context of Brunei Darulsalam. In A.M. Noor et al. (eds.) Strategizing teaching and learning in the 21st century. Proceedings of the International Conference on Teaching and Learning. Faculty of Education: University Kebangsaan Malaysia, Bangi

Sharma, S. K. (1980). Practical and Theoretical Consideration involved in Error Analysis. Indian Journal of Applied Linguistics. VI, 74-83. 